\title{
MOVING BEYOND THE GREEN WALL - OVERCOMING ENVIRONMENTAL PRESSURES
}

\author{
Dr. K. R. Subramanian \\ Professor of Management and Business Consultant
}

\section{SYNOPSIS}

In response to business environment several organizations in the last few decades added a department having responsibility to deal with environmental related issues. Mostly the activities were dominated by legal and regulatory action and the end-of-the-pipe, technically based solutions to these issues. Their position and authority rarely offered the potential for lending value to the firm; more often, they were viewed as a cost center by top management. When businesses' responses to environmentalism have been tied to core business decisions, however, a great deal of organizational change has been requiredincluding overcoming the "Green Wall" between early treatment of environmental issues and the language, tools, and culture of business. Corporate leaders have been driven to evolve over time from early focus on industrial, regulatory, and social responsibility toward a mindset of the natural environment as strategic in nature. This recognition is increasingly important, especially with the rise of broader sustainable development and corporate social responsibility concerns. This recognition is increasingly important, especially with the rise of broader sustainable development and corporate social responsibility concerns. Clearly, environmental management and strategy has reached the executive level in many larger businesses, yet often the Green Wall remains a deeply rooted cultural obstacle in organizations.

\section{KEY WORDS}

Environmental responsibility of Organizations, business response to issues, Focus on regulatory, social responsibility to environmental conservation, Green wall as cultural obstacle to organizations.

\section{INTRODUCTION}

Management research on business and the natural environment has focused on such topics as the description of environmental issues for business, environmental strategy and decision making, environmental accounting and measurement, the content and effects of laws and standards on business, the links between environmental and economic performance, and the relevance of external stakeholder pressure and public disclosure. More recently, the focus of research in environmental management has been on the role the natural environment plays for business decision making in an even broader sensespecifically, sustainability and corporate social responsibility. Green Wall, a term first coined and popularized in the mid-1990s by the consulting firm Arthur D. Little, centers on the concept that the tools used to measure, manage, and lead change in business are not the tools used traditionally by the environmental functions in business. 
The early environmental movement and the following decades painted a moral-ethical picture of the evil corporate interests against nature itself (as represented by environmental organizations and government policy). This good-versus-evil representation has had a strong impact on the behavior of stakeholders within business and outside. Thus, much of the early change efforts from the private sector came from those companies whose mission held core values for the environment from the start. In this case, environmental stewardship throughout business practices was simply the right thing to do. Even today, when environmental leaders within industries (i.e., firms participating in voluntary environmental programs [VEPs]) are surveyed, "the right thing to do" is the most often cited reason for their corporate commitment to the environment.

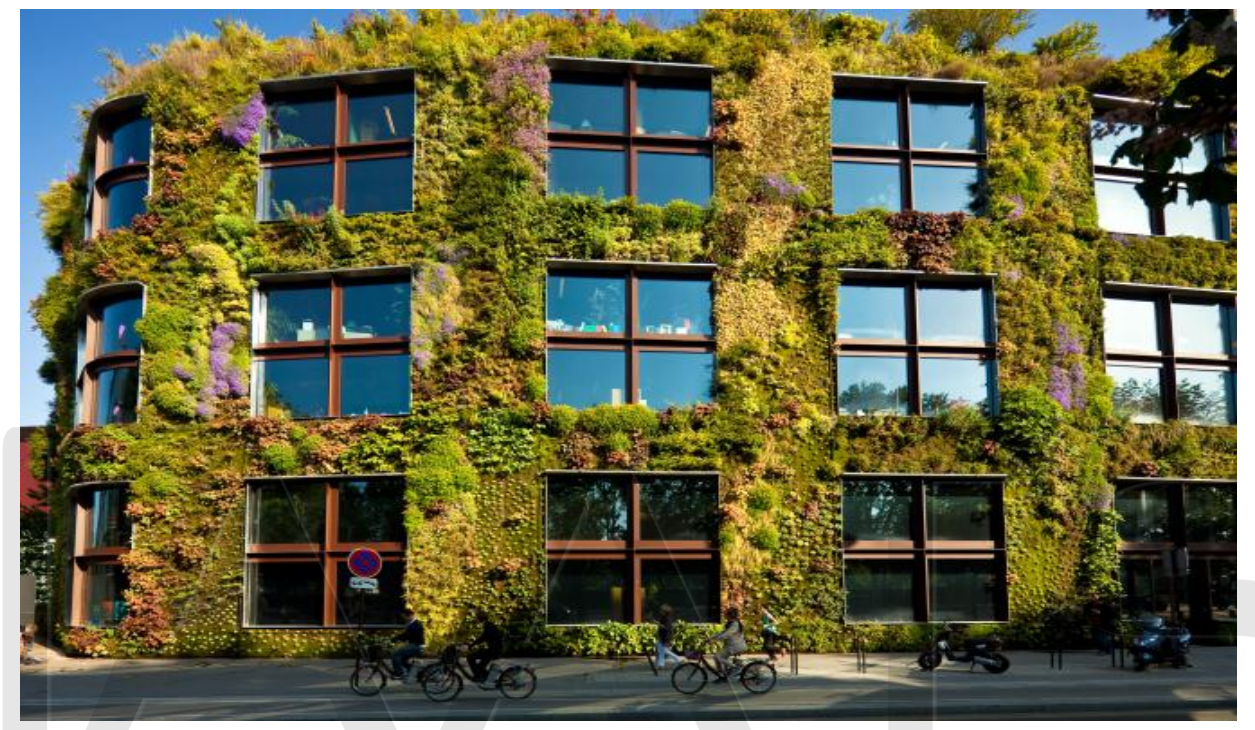

Figure 1: A living wall bursts with vegetation at Paris's Musée du Quai Branly - A type of green wall that's catching on in some big cities.

These vegetated surfaces (Figure 1) don't just look pretty. But they offer other benefits such as, cooling city blocks, reducing loud noises, and improving a building's energy efficiency. What's more, a recent modeling study shows that green walls can potentially reduce large amounts of air pollution in what's called a "street canyon," or the corridor between tall buildings. For the study, Thomas Pugh, a bio-geochemist at the Karlsruhe Institute of Technology in Germany, and his colleagues created a computer model of a green wall with generic vegetation in a Western European city. Then they recorded chemical reactions based on a variety of factors, such as wind speed and building placement. The simulation revealed a clear pattern: A green wall in a street canyon trapped or absorbed large amounts of nitrogen dioxide and particulate matter-both pollutants harmful to people.

Early regulatory pressure fundamentally shaped organizational behavior, with social responsibility models, and eventually, business opportunity models of corporate environmentalism later shaping business behavior toward the natural environment. This directly affected organizational structure for larger firms. Clearly, environmental management and strategy has reached the executive level in many larger businesses, yet 
often the Green Wall remains a deeply rooted cultural obstacle in organizations. The present article aims to analyze the efforts of Corporate Organizations to move beyond the Green wall and would summarize the efforts of present organizations to make this planet more and more inhabitable by conserving the natural resources or at least not destroying them. In cases where research has touched on organizational change and corporate environmental behavior, the focus has been on integrating environmental management through departments. More so, research on the motivations or drivers for business behavior to the natural environment predominantly focuses on moral-ethical, cognitive, coercive-regulatory, competitive, and socially responsible conduct for change.

\section{OBJECTIVES AND METHODOLOGY}

There is growing awareness of the over exploitation of natural resources and the need to conserve them or at least not destroy them. Due to scientific progress and Technological developments organizations tended to overexploit resources for a short term objective of profitability. But social awareness has been aroused through themes of Corporate Social Responsibility and need to conserve the energy and all forms of natural resources. 'Moving beyond the Green wall' is more of a slogan to bring attention to CSR and the organizational commitment beyond the cosmetic changes. With this in view the following objectives were identified for this research paper:

1. A review of Business environment and impact on business.

2. A brief review of Green Wall Concept and its other Avatars.

3. Current Organizational Efforts at overcoming environmental pressures.

4. Future challenges and how organizations can meet them.

5. Suggestions and Action Plans for a better Planet.

Environmental issues have been at the centre stage of organizational concerns and it goes to the credit of several progressive organizations that they have recognized this issue in tie and are taking actions. Green walls have been the beginning of the wakeup call in the organizational efforts and organizations are conscious of the need to put better efforts in conserving natural resources and stop over exploitation - like for example Petroleum resources. The availability of vast literature in the form of published papers has to some extent reduced the burden on the researcher to make a critical evaluation of available literature in the form of published papers and data on the internet and web pages. The author has focused and consolidated the available data to arrive at the conclusions and recommended suitable actions

\section{REVIEW OF LITERATURE}

In order to explore the evolution of the business communities' response to the age of environmentalism - as expressed through environmental crisis, public pressure, the formation of environmental laws, and evolving competitive demands - it is relevant to look at not only the internal elements of business organizations (i.e., structure, staff, and culture changes), but also the external pressures that have shaped corporate environmentalism (i.e., environmental events, regulatory constraints, and public 
demands). Just as technology changes, demographic shifts, and the globalization of business serve as the dynamic backdrop to corporate decisions of price, distribution, and service in the global market place, so too has the age of environmentalism, business decisions, performance, and ultimately, competitive success. From consumer boycotts and demands of consumers to the regulatory and legal environment reflected in the state and federal statutes, a wide array of environmental interests must be managed in today's business operating environment.

American environmental regulatory policy came as a wave of change crashing on the shores of the public and private sectors alike during the 1960s. Rachel Carson's book, Silent Spring, published in 1962, ignited the public and helped spark this new environmental movement. During this decade, Lake Erie was declared dead, the Cuyahoga River in Cleveland caught fire and burned for five days, the nation's proud symbol, the bald eagle, was near extinction from DDT poisoning, and smog in some U.S. cities was often visible and noxious. As a result, public outcry for federal leadership in protecting the country's natural environment and public health took a strong hold of Washington, as well as other state capitals, in the form of legal mandates and regulatory requirements.

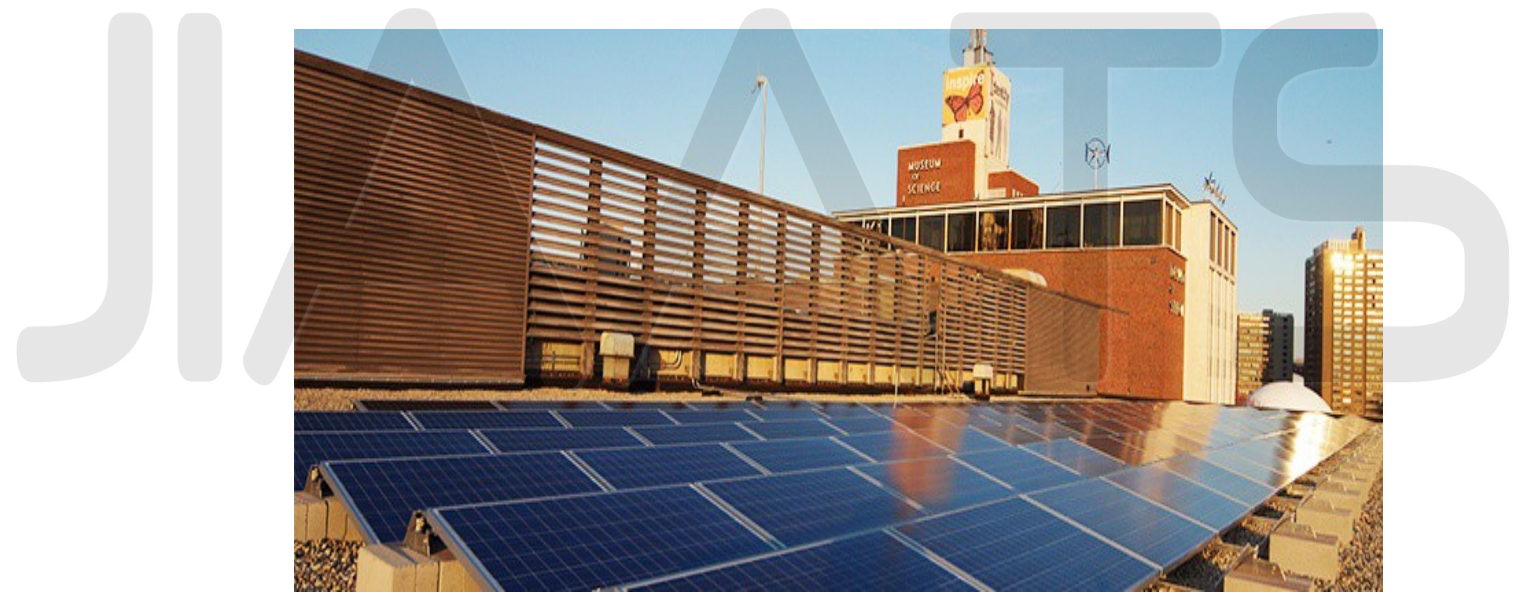

Figure 2: Green Museum of Science, Boston, USA

While human activity was seen as responsible for environmental damage before the 1960s, it wasn't until Rachel Carson's Silent Spring that the public, and eventually political leaders, saw American industry and the products of industrial technology as directly responsible for biotic damage. Nature was seen as finite and fragile. The resultant public outcry - a critical mass of public opinion energizing the first Earth Day, the subsequent creation of the EPA (Environmental Protection Act), and the snowballing federal regulations in response to public demands - created an additional constraining force on private-sector action throughout the 1970s, 1980s, and into the 1990s. The exponential growth of these new legal requirements for business was coupled by an expansion of stakeholder expectations, that is, the expectations of investors, consumers, and environmental groups. 
Today, environmental sustainability is habitually included in day-to-day thinking and visible in the edifice of Green Museum of Science at Boston, USA. In 2000, the Museum began to focus on technology and engineering, a direction that led us to encourage visitors to explore the impact of technology on their lives, our society, and our planet. It was only sensible to apply the critical thinking skills we help develop in our visitors to our own daily work. That process continues today. In 2004, the Museum formed a "Green Building Committee" of Trustees, Overseers, and advisors. One of this group's early contributions was a set of suggestions for the design of the Museum's Gordon Wing that led to a $38 \%$ reduction in the modeled energy consumption of that space compared to the original plans. Exploration of this Environmental sustainability theme led to the creation of the Museum's Sustainability Statement and the establishment of today's "Environmental Sustainability Committee" with a charter to explore and make recommendations pertinent to the Museum's goals and efforts regarding education, facilities and operations, convening of the community, marketing, organization development, and fund-raising. The sections below outline how sustainability has factored into our educational offerings and our facilities and operations.

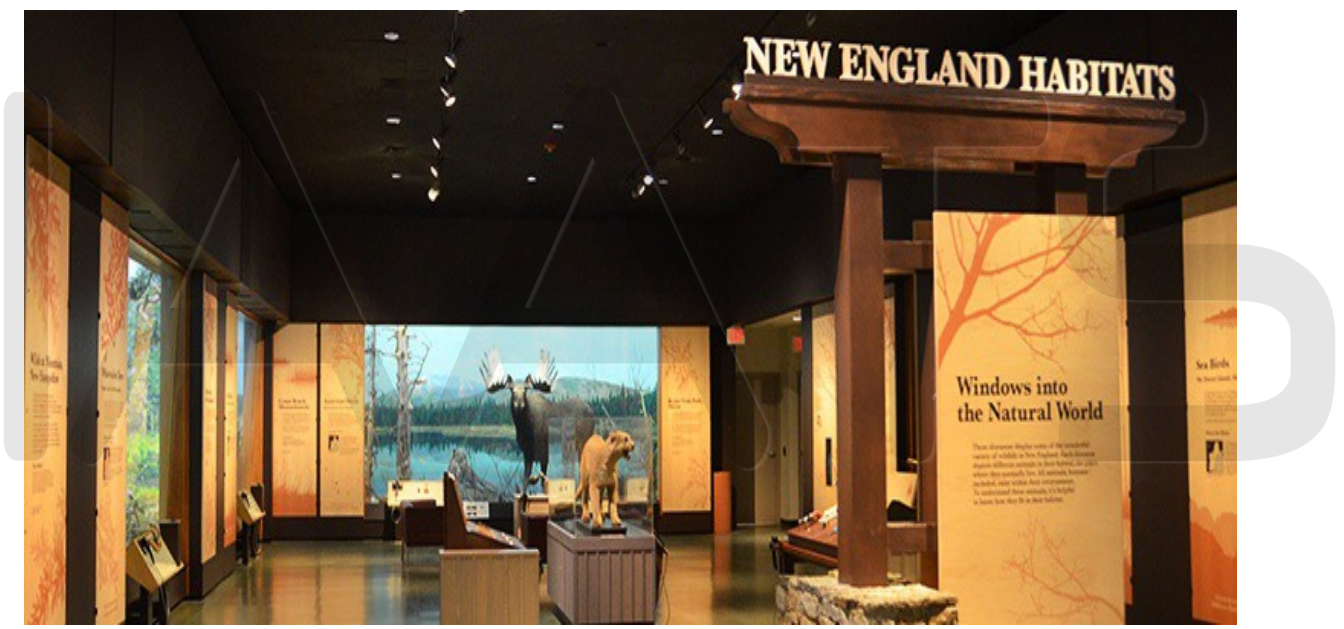

Figure 2.1

One of the Museum's oldest exhibits, New England Habitants was refurbished in 2010.

Using sustainable materials and replacing all lighting with LEDs gives it a fresh, Inviting look and saves considerable energy.

According to data collection and environment assessment studies of World Bank experts, between 1995 through 2010, India has made one of the fastest progress in the world, in addressing its environmental issues and improving its environmental quality. [Still, India has a long way to go to reach environmental quality similar to those enjoyed in developed economies. Pollution remains a major challenge and opportunity for India. Floods are a significant environmental issue for India. It causes soil erosion, destruction of wetlands and wide migration of solid wastes.

Air pollution in India is a serious issue with the major sources being fuel wood and biomass burning, fuel adulteration, vehicle emission and traffic congestion. Air pollution is also the main cause of the Asian brown cloud, which is causing the monsoon to be 
delayed. India is the world's largest consumer of fuel wood, agricultural waste and biomass for energy purposes. Traditional fuel (fuel wood, crop residue and dung cake) dominates domestic energy use in rural India and accounts for about $90 \%$ of the total. In urban areas, this traditional fuel constitutes about $24 \%$ of the total. Fuel wood, agricultural waste and biomass cake burning releases over 165 million tonnes of combustion products into India's indoor and outdoor air every year. These biomass-based household stoves in India are also a leading source of greenhouse emissions contributing to climate change.

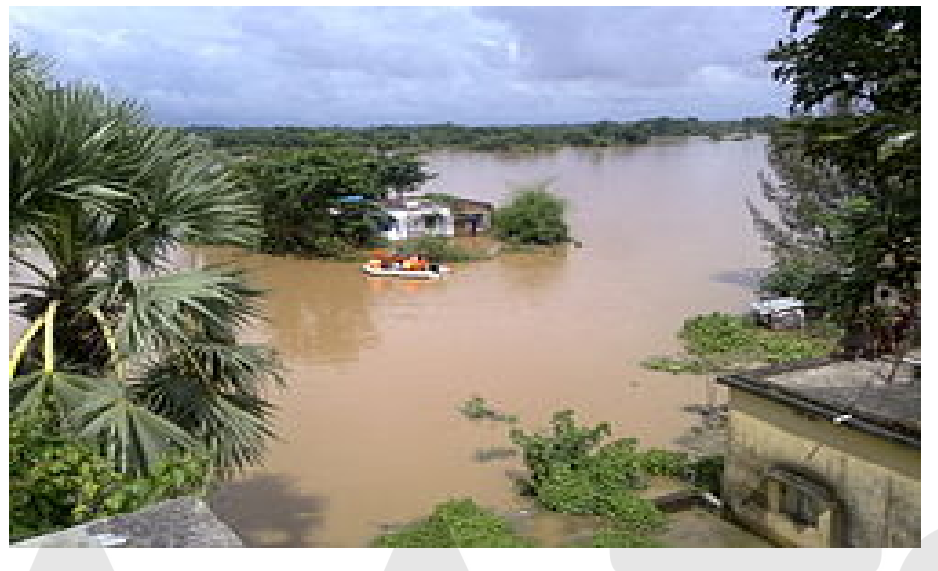

Figure 3: Environmental issue of floods in India

India is vulnerable to various natural hazards, particularly cyclones and annual monsoon floods, and various combinations of poverty, population growth, increasing individual consumption, industrialization, infrastructural development, poor agricultural practices, and inequality in resource distribution have led to substantial human transformation of India's natural environment. An estimated 60 percent of cultivated land suffers from soil erosion, water logging, and salinity. It is also estimated that between 4.7 and 12 billion tons of topsoil are lost annually from soil erosion. From 1947 to 2002, average annual per capita water availability declined by almost 70 percent to 1,822 cubic meters, and overexploitation of groundwater is problematic in the states of Haryana, Punjab, and Uttar Pradesh. Forest area covers 19.4 percent of India's geographic area (63.7 million hectares). Nearly half of the country's forest cover is found in the state of Madhya Pradesh (20.7 percent) and the seven states of the northeast (25.7 percent); the latter is experiencing net forest loss. Forest cover is declining because of harvesting for fuel wood and the expansion of agricultural land.

The historical response to environmental management pressures by larger firms varies only slightly among researchers. Early regulatory pressure fundamentally shaped organizational behavior, with social responsibility models, and eventually, business opportunity models of corporate environmentalism later shaping business behavior toward the natural environment. This directly affected organizational structure as well for larger firms. A clear expansion of staffing occurred. Multinational corporations created a whole infrastructure of units at different levels - corporate, division, and facility - as well as coordinating functions. In addition, many of them created positions of vice presidents 
for environmental affairs. With this, a new leadership position was born in corporate structures - the chief environmental officer. Yet, from Wal-Mart to General Electric, many leading corporations are continuing to find the business value of environmental strategy.

Like the evolution of environmental regulation, the actions and interests of the press and media, interest groups, and the external manifestation of crisis management have also shaped corporate environmental strategy. An examination of broader management of social and political issues and the institutional response by larger firms to press coverage and interest group pressure shows that firms adopted external scanning mechanisms, environmental communications departments, and long-range strategies as a result of these nonmarket pressures as well. Leading firms have come to manage threats and opportunities related to the natural environment in a way that includes public perception.

Market studies in the United States have also indicated that consumers can be drivers for environmental-preferable products and can be segmented into specific categories based on environmentally related product-purchasing tendencies, specifically (Roper Starch/S. C. Johnson \& Son, Inc. 1993)

- $10-15 \%$ are True-Blue Greens - very committed to the environment and will pay more for an environmentally preferable product or service;

- $10 \%$ are Greenback Greens - also committed to the environment, but not as likely to pay more for a specific environmental product;

- 50-55\% are Half-Greens - express concern, but act erratically as a buyer, occasionally taking environmental performance into consideration of buying decisions; and

- $30 \%$ are Basic Browns - either too poor to focus on environmental issues as a buyer or simply do not care about the environment.

The leading segments of customers have served to spur a green-consumer movement in the United States - something that evolved years before in places like Europe. This factor is increasingly important to corporate strategists in the age of global competition. When environmental performance is wrapped together with corporate citizenship and measures of sustainability (including economic, environmental, and social-management issues) for companies, the landscape for success in business becomes murky, untested, and frightening. Yet, this growing segment of green consumers is also driving the need for businesses of all types to better integrate environmental concerns in day-to-day operations. Other external facets that have been driving behavior on the natural environment for larger firms include the following:

1. Banks are faster to lend to companies that prevent pollution and avoid risk.

2. Insurance companies are more eager to underwrite clean companies and see environmental leadership as a signal of a well managed (i.e., less risky) company.

3. Employees want to work for environmentally responsible companies, especially as an increasing number of younger employees enter the workforce. This trend will only continue as more baby boomers reach retirement age. 
4. Clean companies are rewarded with relief from green taxes and charges; over time this may evolve into rewards for carbon neutrality as global warming continues to evolve as a business topic.

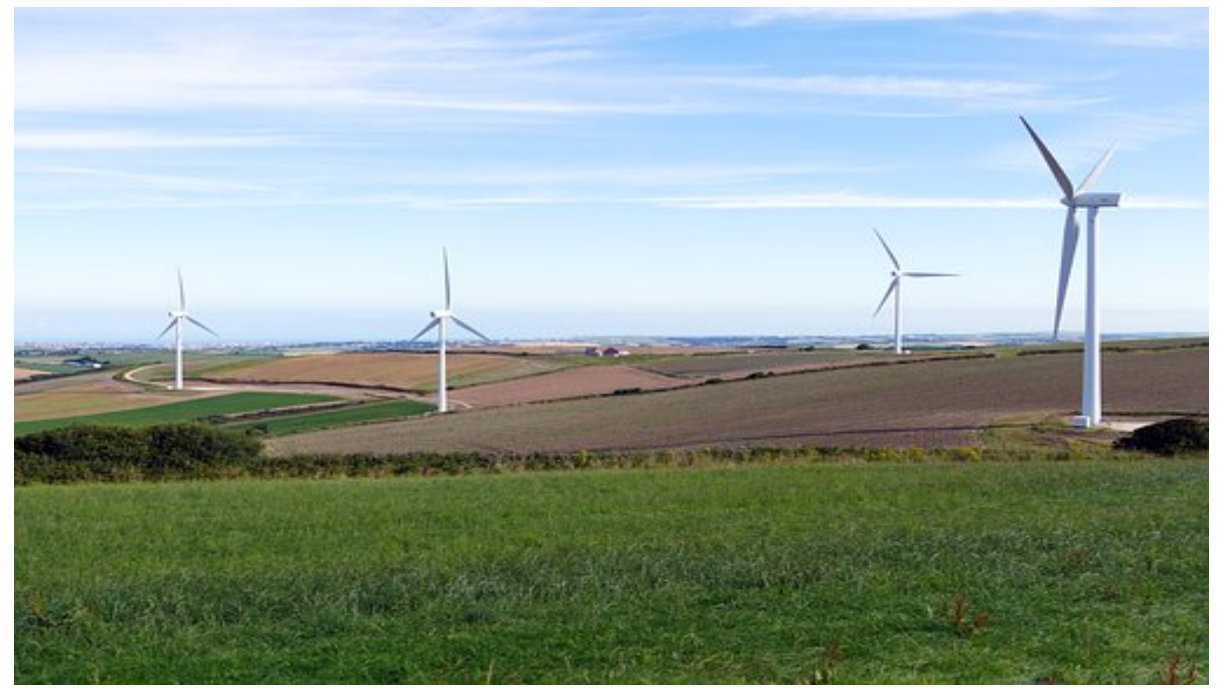

Figure 4: Alternate sources of energy

5. Recently, environmental management has grown to be included as an element of the broader sustainable development and corporate social responsibility literature. The commonly accepted definition of sustainable development or sustainability is development that meets the needs of the present without compromising the ability of future generations to meet their own needs. As markets become increasingly closer globally, multinationals will be the first to find it difficult with the transboundary, intergovernmental, and socially rich matrix of sustainability.

6. A central issue to sustainability research is if and how to harness the enormous power of the private sector to serve all of society. Emerging research perspectives on corporate sustainability acknowledge that businesses can play a fundamental role in achieving social objectives, but that in practice this requires an understanding of multi-stakeholder collaboration and partnering, resulting in new capabilities as a result of those partnerships, which challenge traditional business assumptions.

7. The social principles of justice and inclusiveness, embedded in sustainable development, have entered the corporate agenda, even among firms making promising environmental efforts at a global scale. Corporate social responsibility research has focused on three main areas with respect to environmental management: (a) developing descriptions of the evolution of corporate environmental practices; (b) explaining external and internal drivers of why organizations adopt environmental practices; and (c) examining the link between proactive or beyond compliance environmental practices and profitability. This integration of corporate social performance with environmental performance presents a challenge to identify meaningful sustainability metrics instead of focusing on pollution or environmental data 
Like any corporate change initiative, developing a significant power base throughout the upper levels of the organization on an environmental initiative is necessary. If the intended change involves the total redirecting of environmental behavior by the firm, this coalition becomes crucial. This coalition determines the depth of influence a change initiative will have in the organization. Only recently have environmental issues permeated to the upper layers of corporate decision making-the needed layer for creating coalitions that break organizational inertia and allow for change to occur. Leadership defines an organization's vision and is related to the need for top management commitment and the coalition-building steps. Likewise, a stated vision responds to crisis - created or actual - that helps trigger change throughout an entire organization. It is the focused, total response to that urgent environmental responsibility and corresponding business goal. The formation of corporate vision and mission statements to address environmental concerns beyond mere regulatory requirements serves as an example in larger firms.

Along with a weak sense of vision, environmental change initiatives have often been stifled by a simple lack of commitment throughout the organization. With any type of organizational change, people often have difficulty because of the sheer magnitude of the task. Getting people to understand and accept a particular vision is usually an enormously challenging undertaking. This lack of communication among environmental staff and other members of the company are at the heart of the Green Wall phenomenon. Once again, the historic treatment of environmental management concerns by business has created divisions among environmental staff and the rest of the company. Ultimately, at the heart overcoming the Green Wall in organizations is an understanding of how individual change agents lead efforts for voluntary environmental leadership. The rigid history of business environmentalism and respective influence on business environmental behavior makes this type of organizational change a difficult task. A full understanding of organizational change is needed, as is an understanding of the role of the environmental champion in that process.

\section{ANALYSIS OF DATA AND CONCLUSIONS}

Environmental pressures on business to conserve the natural resources and reduce harmful emissions were met with the corporate response of creating a 'Green Wall', a cosmetic change to reduce the effects of emission. Subsequently the business organizations found out that such responses were inadequate to meet the growing demand of public outcry against the exploitation of natural resources by corporate companies and the depletion of even the oxygen content in breathing air. The green wall gave way to a rising corporate consciousness on environmental conservation and the corporate companies started taking environmental protection seriously through legislation and preventive actions by designing and modifying the manufacturing processes.

'Green wall' is often seen as the beginning of a new era of corporate consciousness on environmental issues. Self regulated and stringent laws were introduced for pollution control and subsequently through various other forms of measurement of compliance. Today organizations are not only concerned with compliance, they are serious about the 
future of industries. General lack of commitment was replaced by a consciousness on environmental issues as reflected by self regulation and a systematic effort to make the world a better place to live.

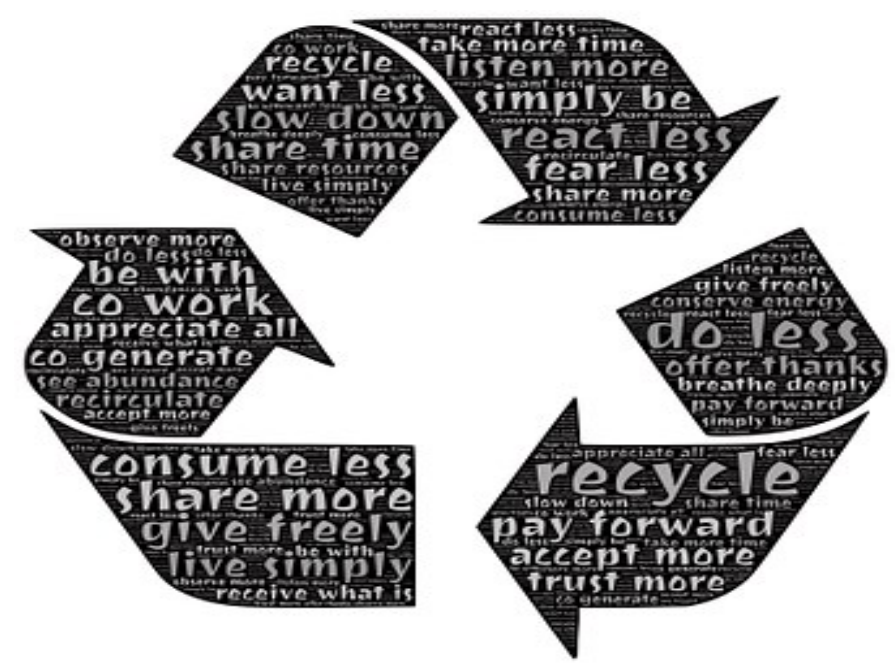

Figure 5: Messages on conservation to remind us

Current efforts are reflected by environmental studies and voluntary efforts on conservation. The progress of Green Museum in USA and other countries is a reflection of human concern on environmental issues and effective action to squarely meet them. Green consumer movements, the drivers of corporate behavior as reflected in corporate policies like banks' lending policies in favor of green companies, insurance companies and ultimately employees themselves preferring to work in environmental friendly companies are examples of this new wave of consciousness spreading. CSR initiatives have included sustainability as a main focus.

Future challenges include compliance of companies to this new philosophy and not exploiting overly the natural resources like petroleum. It is heartening to note that research on alternate forms of energy and incentives for development of wind and solar energy substitutes are making good progress in developing countries like India. Future is no more a distant dream but a current reality to be tackled with seriousness and commitment by organizations. Product development and promotion of companies should reflect this attitude to environmental awareness.

\section{RECOMMENDATION}

Suggestions and Action Plans seem to be redundant as the author feels that organizations are already possessed of the gravity of the situation. Governments can accelerate this process through mutual cooperation and exchange of ideas. In a world full of conflict based on flimsy and narrow issues this may look like a far cry. But the reality is that human existence depends on the cooperation of nations and commitment to sustainability by forgetting the narrow concerns and conflicts based on that. 


\section{REFERENCES}

1. Accolade, M. (2003, June). European and U.S. multinationals place different emphases on corporate sustainability, PricewaterhouseCoopers finds: Environmental and social performance a priority for Europeans; an opportunity for Americans. Management Barometer.

2. Berry, M. A., \& Rondinelli, D. A. (1998). Proactive corporate environmental management: A new industrial revolution. Academy of Management Executive, 12(2), 38-50.

3. Brundtland, G. (1987). Our common future: The world commission on environment and development. Retrieved August 31, 2007, from http://www.un.org/esa/sustdev/publications/pub lications.htm

4. Cairncross, F. (1991). Costing the earth: The challenge for governments, the opportunities for business. Boston: Harvard Business School Press.

5. Darnall, N., Carmin, J., Kreiser, N., \& Mil-Homens, J. (2003, December). The design \& rigor of U.S. voluntary environmental programs: Results from the VEP survey de Steiger, J. E. (1997). Age of environmentalism. New York: McGrawHill.

6. Dickinson, E. (2000). Editorial column. BOAT/US Magazine, 11, 28-29.

7. Easterbrook, G. A. (1995). Moment on the earth: The coming age of environmental optimism. New York: Pengiun Books.

8. Elkington, J. (1998). Cannibals with forks: The triple bottom line of 21st century business. Gabriola Island, British Columbia, Canada: New Society Publishers. Fischer, K., \& Schot, J. (Eds.). (1993). Environmental strategies for industry: International perspectives on research needs and policy implications. Washington, DC: Island Press.

9. Frankel, C. (1998). In earth's company: Business, environment, and the challenge of sustainability. Gabriola Island, British Columbia, Canada: New Society Publishers.

10. Hoffman, A. (1998). From heresy to dogma: An institutional history of corporate environmentalism. San Francisco: New Lexington Press.

11. Hoffman, A. (2000). Corporate environmental strategy: A guide to the changing landscape. Washington, DC: Island Press.

12. Kanter, R. M. (1983). The change masters: Innovation and entrepreneurship in the American corporation. New York: Simon \& Schuster.

13. Kotter, J. (1996). Leading change. Boston: Harvard Business School Press.

14. Kotter, J., \& Heskett, J. L. (1992). Corporate culture and performance. New York: Free Press.

15. Petulla, J. M. (1988). American environmental history. Columbus, OH: Merrill Publishing Company.

16. Piasecki, B. (1995). Corporate environmental strategy: The avalanche of change since Bhopal. New York: John Wiley \& Sons.

17. Piasecki, B., Fletcher, K., \& Mendelson, F. (1999). Environmental management \& business strategy: Leadership skills for the 21st century. New York: John Wiley \& Sons. 
18. Reinhardt, F. L., (2000). Down to earth: Applying business principles to environmental management. Boston: Harvard Business School Press.

19. Rondinelli, D., \& Berry, M. (2000). Corporate environmental management and public policy: Bridging the gap. The American Behavioral Scientist, 44(2), 168187.

20. Roper Starch/S. C. Johnson \& Son, Inc. (1993). The environment: Public attitudes and individual behavior, North America: Canada, Mexico, United States. Racine, WI: Roper Starch.

21. Schein, E. H. (1992). Organizational culture and leadership (2nd Ed.). San Francisco: Jossey-Bass.

22. Schmidheiny, S. (1993). Changing course: A global business perspective on development and the environment. Cambridge, MA: MIT Press.

23. Shelton, R. (1995). Hitting the green wall: Why corporate programs get stalled. Corporate Environmental Strategy: The Journal of Environmental Leadership, 4(3), 34-46.

24. S. Bureau of Census. (2000). Statistics of U.S. businesses. Retrieved April 15, 2004.

25. Winsemius, P., \& Guntram, U. (1995). Towards a top management agenda for environmental change. Amsterdam: McKinsey \& Associates.

26. Ramesha Chandrappa and Ravi.D.R, 2009, Environmental Issues, Law and Technology - An Indian Perspective Research India Publication, Delhi.

27. Milind Kandlikar, Gurumurthy Ramachandran (2000). "2000: India: the causes and consequences of particulate air pollution in urban India: A Synthesis of the Science". Annual Review of Energy and the Environment. 25: 629-684.

28. World Health Organization (1992), Our Planet, our Health: Report of the WHO Commission on Health and Environment, Geneva

29. National Geographic Society. 1995. Water: A Story of Hope. Washington (DC): National Geographic Society

30. Kirk Smith et al., Greenhouse Implications of Household Stoves: An Analysis for India, Annual Review of Energy and the Environment, Vol. 25: pp 741-763

31. Gadde et al., Air pollutant emissions from rice straw open field burning in India, Thailand and the Philippines, Environmental Pollution, Volume 157, Issue 5, May 2009, Pages 1554-1558

\section{WEB REFERENCES}

1. http://www.barometersurveys.com/production/barsurv.nsf/vwNewsDocsPrint/E73 FD3683C831B9985 256D3A0067F230?OpenDocument

2. https://osf1.gmu.edu/ ndarnall/docs/VEP_Survey_Report.pdf

3. http://quickfacts.census.gov/ qfd/states/55000.html

4. http://www.sba.gov/advo/research 